\title{
Supplier qualification for high value goods and services in Nigeria: A comparison of qualified and non-qualified suppliers
}

\begin{abstract}
This study set out to understand the capabilities of suppliers of high value products and services in Nigeria. Supplier capability data was collected from almost 500 potential suppliers across 28 product categories. The findings indicate that only a small minority of potential suppliers achieved the required levels of performance and that very few companies have suitable operational capabilities or corporate citizenship behaviour. Furthermore, significant differences were found between service suppliers and product suppliers with regard to performance. The findings suggest that the majority of suppliers of products and services in Nigeria need to improve their operational capabilities and corporate citizenship behaviours or else risk losing their ability to compete in a changing market place with new barriers to entry.
\end{abstract}




\section{Supplier qualification for high value goods and services in Nigeria: Understanding the competitive environment}

\section{Introduction}

The management of the purchasing process for goods and services is an important aspect of supply chain management. Previous research has shown that many organisations have explored and exploited the potential of purchasing synergy or pooled purchasing power [1, 2]. According to Goold and Campbell [3] pooled purchasing is typified by a head office facilitating centralised buying. This study presents a case study on the qualification of suppliers for pooled purchasing of high value goods and services (hereafter referred to as major goods and services) by one of the largest service organisations in Nigeria, ServiceOrg.

The study seeks to understand the factors that differentiate suppliers that are prequalified to bid for goods and services from those that fail the pre-qualification process. Consequently, it will be possible to identify the strengths and weaknesses of the potential supplier pool, discuss its impact on competitiveness and propose solutions that would improve the performance and competence of potential suppliers. There are few studies examining operations management in African countries (and Nigeria in particular) and this research contributes to filling that knowledge gap. With a population of about 160 million, Nigeria is the most populous African country and one of its largest and fastest growing economies. Management practices in developing economies have been found to lag those in developed economies [4]; if developing economy countries are to improve their business environment and performance, there is a need to identify and improve on weaknesses in the management of their organisations. 
From the perspective of the case study organisation, this study is motivated by the need to improve competitiveness; improved competitiveness is underpinned by the ability to reduce prices, improve efficiency and reduce the supplier base $[5,2]$. In particular, the high value nature of the goods and services considered implies that these are major costs for the organisation and this therefore provides significant scope for cost reduction. This study also examines the supplier qualification process for a range of major goods and services and identifies the performance factors that define success within the study context. The process of supplier qualification was being instituted for the first time at the case study company (ServiceOrg) and this is representative of an increasing trend among Nigerian businesses.

The importance of this qualification process to ServiceOrg (and other such organisations in Nigeria) cannot be overemphasised. For example, the supply of electricity within Nigeria is very sporadic and organisations spend very significant sums of money to generate independent power [6]. It has been estimated that the cost of power for manufacturing companies in Nigeria is between 30 and $35 \%$ of their production cost [7]. ServiceOrg needs to generate its own power for as much as $90 \%$ of the time in some locations and consequently the purchase and maintenance of power generating sets and continual supply of diesel is not only critical to its operations but also represents a significant cost that needs to be adequately managed.

This paper is structured as follows: the next section presents the objective and research questions and is followed by a discussion of literature relevant to the study. This is followed by the methodology used in the study and the presentation of the key findings. The findings are then discussed before the study conclusions are presented. 


\section{Research objective and questions}

In order for suppliers to be successful, they must first be able to achieve the order qualifiers of the customer. For ServiceOrg, the opportunity to restructure and streamline the purchasing process will lead to greater transparency and fairness in the process as well as reduced costs through aggregated purchasing, the reduction of 'maverick' buying and the elimination of multiple purchasing processes across the organisation. The objective of this study is to investigate and compare the performance of product and service suppliers in Nigeria within the context of the introduction of new supplier pre-qualification criteria. The findings from the study will contribute to an understanding of performance capabilities and developmental opportunities for suppliers in countries such as Nigeria.

In order to achieve the objective above, the qualification process of ServiceOrg was examined and four research questions that support the research aims were identified as follows:

Research Question 1. How do Nigerian suppliers perform when assessed against operational capability and corporate citizenship qualification criteria set by a customer?

Research Question 2. What are the differences between suitably qualified potential suppliers and unqualified potential suppliers and what are the factors that are critical to qualification?

Research Question 3. How does the level of performance of the potential suppliers affect their competitive positioning?

Research Question 4. What priorities do stakeholders in Nigeria need to focus on in order to improve the level of performance and competence of the supplier community in Nigeria? 


\section{Literature review}

The decision of choosing suppliers involves a plethora of factors and as a result is a rather complicated process; however, choosing the correct suppliers for individual goods and / or services is one of the most important contributors to the success of any organisation [8 11]. The role of the purchasing function with respect to identifying and selecting suppliers is, therefore, an important one. Over time, an increase in purchasing activity in organisations has facilitated the development of the purchasing function and increased its level of influence $[12,13]$. The use of this increased power has become increasingly important in situations where purchasing is centralized within a large organisation. Methods for selecting the right suppliers have been studied since the 1960s with Voss [14] suggesting that the most important criteria are price, quality and delivery reliability. Similarly, different types of performance measurement metrics which may be product, supplier or society-related have been developed [15] and a number of concepts relating to supplier selection and supplier performance have also evolved; these include theories on competitive priorities and order qualifiers/winners. Competitive priorities reflect the strategic decision taken by manufacturers and form the basis of how the organisation intends to compete with others [16]; competitive priorities that have been identified include cost, quality, delivery, product variety and flexibility [17]. Competitive priorities have also been found to have an influence when determining practices and performance within organisations [18] and can serve as a basis for launching action plans across a range of categories including facilities, capacity, quality management and human resource management [19]. Such practices and performance would need to meet the requirements and expectations of potential customers for the supplier to qualify for and win orders. Horte and Ylinenpaa [20] described 
an organisation's competitiveness as its ability to win orders in the marketplace while Quesada et al. [21] suggested that competitive priorities can be considered to be a generalisation of order qualifiers and winners.

\subsection{Order qualifiers and winners}

The concept of order qualifiers and winners was developed by Hill [22]; order qualifiers are the set of criteria that an organisation must meet in order for the customer to regard it as a potential supplier, while order winners are the set of criteria that suppliers must meet in order to actually win the orders. Order qualifier criteria are the necessary criteria for organisations to enter into and remain in the market, and an organisation's performance in these criteria therefore needs to be at least as good as their competitors. For organisations to be considered Order winners, they need to be better than their competitors; therefore, once organisations have order qualifier criteria in place, they then need to focus on order winners [23]. Understanding order winners can enable a supplier to implement the required supply chain solutions [24]. However, this may not straightforward or easy as Horte and Ylinenpaa [20] noted that there may be incongruence in the suppliers' and customer's views on order qualifiers and winners. They further suggested that a supplier may not always understand the customer's decisions, or their values or perceptions of rival suppliers.

The primary focus of this study was on order qualifiers as it was an exploratory exercise for ServiceOrg. The numerous offices of the organisation had previously been responsible for sourcing many products and services independently, resulting in huge variations in cost, quality and effectiveness and thereby leading to process inefficiency within some branch offices. The primary goal of qualifying suppliers was to gather knowledge on the capabilities 
of potential suppliers and identify a supplier base that meets the minimum requirements of ServiceOrg, thereby improving the effectiveness of the purchasing process within the organisation.

\subsection{Supplier selection and development}

With increasing trade between African and global organisations, the relatively low level of industrial development in many African countries implies a dependence on manufactured components and goods from other parts of the world. To improve their performance, it is important to understand the importance of supply chain management, in particular the role of supplier selection. By identifying the current level of performance of the supplier base in countries such as Nigeria, it would be possible to understand their developmental needs and, consequently, propose actions that would address these needs.

An understanding of the current level of performance also provides important insight into the levels of competitiveness in countries such as Nigeria. According to [25] companies can gain competitive advantage by creating products and services that are both different from and better than their competitors. Factors that relate to competitiveness were further highlighted by Porter $[26,27]$ and include items such as the level of supplier bargaining power, the level of buyer bargaining power, the barriers to entry into the market and the threat of new entrants. Within the context of this study, ServiceOrg's legacy approach to supplier selection presented little or no barriers to entry for potential suppliers and would have been characterised by a high level of competition among suppliers, giving ServiceOrg significant bargaining power. However, the decision to restructure the supplier selection process could have significant impacts on the competitive positioning of ServiceOrg and its 
potential suppliers. Therefore, it is important to understand whether the introduction of a qualification exercise would, based on Porter's view, enable ServiceOrg or its suppliers to differentiate themselves.

\section{The Nigerian context}

Nigeria is the Africa's most populous country with a population of around 160 million. It is also one of Africa's largest economies with a GDP of US\$193.6bn [28] and one of the top 10 producers of oil in the world. According to the World Bank [28], Nigeria is ranked $44^{\text {th }}$ in the world with regard to GDP and $31^{\text {st }}$ in the world in terms of purchasing power parity (PPP). It's important oil industry and its relative wealth within the context of Africa and other developing countries makes it an attractive business destination for many global businesses.

However, inspite of its wealth of natural and energy resources, the country is beset by enormous infrastructure challenges. These challenges include the generation of electricity and the provision of an adequate transportation network [6, 7]. Okafor [6] further described power supply to virtually all Nigerian states as dismal. The impact of the difficult business environment is that several manufacturing companies have ceased to operate in Nigeria and those that remained in operation produced goods at a high cost relative to their counterparts in other countries. In a 2007 report by Okonjo-Iweala [29], who later became a two-time Minister of Finance in Nigeria and a Managing Director of the World Bank, it was noted that several initiatives had been taken to improve developmental issues in Nigeria [29]. However the report also noted that more needed to be done in terms of improving the domestic business climate and improving infrastructure. 
The difficulties in the provision of infrastructure have had an enormous impact on the industrial development of Nigeria and consequently, crude oil production, services and agriculture are the biggest contributors to GDP. In the absence of a large industrial base, the provision of services to such a large population means that the service sector (including telecommunications, finance and banking, and petroleum retailing) is the sector of choice for both employment and the provision of goods and services. A relatively small number of large organisations with nationwide operations and increasing presence in other African countries dominate these sectors and, unsurprisingly, their business is highly coveted by the supplier community. The provision of high value goods and services, and the perceived large profit margins, implies that suppliers are often in fierce competition to become providers of choice for these large organisations.

\subsection{ServiceOrg - the buyer organisation}

ServiceOrg is a major player in one of Nigeria's most vibrant service sector industries and has more than 200 offices across the country. The organisation employs more than 1,500 people and its nature as a service organisation implies that much of its purchasing activity relates to MRO inventory. However, goods and services of high value are, in many cases, critical to the organisation for cost and/or operational reasons. For example, all offices across the country had to generate their own power most of the time, as a lack of power in any office implied a complete shutdown of all operations at that office and an inability to serve customers. This results in a requirement of powerful and expensive generating sets for all locations and an almost daily replenishment of diesel fuel. The purchase of official cars is another product of high value. The cars are required for senior executive officers, marketers 
and for the operations department. Each office across the country maintains a car pool and the head office has a fleet of several dozen cars.

A total of 28 categories of major spending were identified for this study. Clearly, these were products and services that were procured at a very high cost, and the inability to control such costs had huge financial implications for ServiceOrg. The legacy purchasing process for major products and services involved decisions being taken at either a local or regional level; consequently, decisions on supplier selection and actual purchasing were usually taken by a small number of senior regional or local managers. The implications for the organisation were twofold: firstly, there was a multiplicity of purchasing operations across the organisation's various offices and, predictably, the levels of effectiveness of the process varied significantly from one office to the next. Much of these variations were the result of choosing suppliers with low levels of competence and/or poor service levels; for example, there were instances where operations were shut down either because a supplier had failed to supply fuel for the power generators or the generators had broken down and the required parts could not be sourced readily. Secondly, the costs of such purchases varied significantly across the organisation; as a result, opportunities to buy from the best suppliers as well as to aggregate spending across the organisation were lost.

Driven by a vision to be the best in its sector, ServiceOrg recently made a number of significant changes to its policies and processes. The procurement function was singled out and was given the objective of adopting best practices in supplier selection and management. In order to standardise purchasing and introduce objectivity and transparency into the processes of supplier selection, registration and appraisal, a nationwide exercise was conducted with the aim of identifying and evaluating potential suppliers for major 
products and services based on a number of criteria. The two most important criteria accounted for $50 \%$ of the election decision and included i) the financial capability, and ii) the management capability. Financial capability was critical as the products and services were of high value and it was therefore important that the selected suppliers had a financial base strong enough to ensure continuity of services. Management capability was important to ensure that senior personnel had adequate experience in the provision of the required goods and services in order to guarantee a high level of service delivery.

The procurement unit of ServiceOrg was staffed by 15 people, of which two were senior managers. The procurement team was required to identify and categorise products and services required by ServiceOrg based on spend value, frequency of usage, number of vendors, the criticality of the product or service and the challenges in sourcing the product or service. This resulted in the identification of the 28 categories of high value products and services.

\section{Research Methodology}

Action research methodology was used in this study, with data being collected using the participant-as-observer role. Burns [30] noted that action research is characterised by four factors which were present in our study context; these factors include i) situational - a problem in the context of the organisations is diagnosed and attempts are made to solve it; ii) collaborative - researchers and practitioners work together throughout the research; iii) participatory - team members are directly involved in implementing the research, and; iv) self-evaluative - modifications are continuously evaluated to improve practice.

In the participant-as-observer role, a researcher becomes an active member of the group and, therefore, gains a deeper appreciation and higher levels of insight of the group [31]. 
One of the authors conducted this role of participant-as-observer, allowing them to provide facilitation to the entire group as well as an independent, external opinion during meetings. The author also designed the scoring and ranking matrix and managed the study data.

\subsection{Data Collection}

The data collection process started by identifying 28 categories of products and services in the major spend category. The category was primarily defined based on the overall amount of money spent by the organisation across its different offices based on historical data of the most recent 2 or 3 years $(2008-2011)$. Thereafter, a set of criteria to be met by potential suppliers was agreed and a scoring matrix designed to give a maximum score of 100. The criteria were determined by managers of ServiceOrg and were based on the operational capabilities and corporate citizenship behaviours they expect from their supplier base. For example, ServiceOrg would expect its suppliers to be financially stable, pay their taxes and ensure that employees work in a safe environment. The three most important criteria for qualification were based primarily on the financial stability and level of knowledge/competency of the potential suppliers. The high value nature of the products and services and the fact that suppliers would not be paid until the goods and services had been delivered meant that it was important that potential suppliers show a suitable level of financial stability and/or access to funding that would enable ServiceOrg to consider them as a reliable supplier. The specialised and/or technical nature of some of the goods and services (e.g. supply and maintenance of power transformers, supply and maintenance of lifts) also meant that it was vital that qualified suppliers had both the technical knowledge and a successful track record to enable them to provide high quality goods and services. 
Table 1 shows the details of the 28 categories of the major products and services, the acceptable minimum performance per category, the number of responses received (i.e. the number of organisations that applied to be suppliers for that category) and the number of supplier bids that achieved the minimum performance (i.e. the number of potential suppliers that were deemed to be order qualifiers after they had provided evidence of their working practices). The specification of the minimum acceptable performance was decided by ServiceOrg based on the organisation's determination of the level of importance of each criterion to its operations and the technical complexities of each criterion. For example, the construction and maintenance of buildings, supply of courier services and supply and maintenance of transformers and power equipment are all crucial to operations and/or require high levels of technical skills and consequently, the required minimum performance was relatively high. On the other hand, supply of painting services and supply of fuel for generators were either less critical to operations or required less technical skills and were, consequently, assigned lower minimum performance for qualification.

A linear weighting model as described by De Boer et al. [32] was used; this model is characterised by the assignment of weightings to selection criteria with the most important criteria having the largest weightings. The qualification criteria used are shown in Table 2. As indicated by Table 2, financial capability and management capability accounted for 30 and 20 points out of 100 respectively, while references that showed a successful track record accounted for 14 points.

The data was collected based on evidence and documentation presented by potential suppliers. Adverts were place in major national newspapers in the country inviting potential suppliers to submit company information and evidence to support fulfilment of the required 
criteria. This method was chosen as it was the best way of obtaining nationwide data due to there being no national database of organisations providing such products and services in the country. In addition, this method ensured fairness and maintained a level playing field for all potential suppliers. The total number of responses received across all 28 categories was 494 . This is a relatively high number of responses for these categories of products and services even though there are many more organisations within the country that can provide the products and services required by ServiceOrg. The list of bidding organisations included major multinational organisations, major national businesses listed on the stock market, and smaller private or family businesses. Some categories were more competitive than others and attracted more bidders (as shown in Table 1).

Table 1. List of all 28 categories, the acceptable minimum performance, number of responses received and number of responses achieving the minimum acceptable performance

\begin{tabular}{|c|c|c|c|c|}
\hline Category & $\begin{array}{l}\text { Product / } \\
\text { Service }\end{array}$ & $\begin{array}{l}\text { Minimum } \\
\text { Performance }\end{array}$ & $\begin{array}{l}\text { Number of } \\
\text { Responses }\end{array}$ & $\begin{array}{c}\text { Number of responses } \\
\text { Achieving Minimum } \\
\text { Performance }\end{array}$ \\
\hline Supplyand Maintenance of Generators & Product & 65 & 34 & 5 \\
\hline Supply and Maintenance of Air Conditioners & Product & 60 & 16 & 4 \\
\hline Supply of Office Furniture a nd Fittings & Product & 60 & 17 & 5 \\
\hline Supply a nd Maintenance of Specialised Equipment & Product & 60 & 20 & 6 \\
\hline $\begin{array}{l}\text { Supply and Maintenance of Safety, Security and } \\
\text { Environmental Equipment }\end{array}$ & Product & 70 & 30 & 9 \\
\hline $\begin{array}{l}\text { Supply a nd Maintenance of Photocopiers and } \\
\text { Accessories }\end{array}$ & Product & 65 & 9 & 6 \\
\hline Supply of Toners & Product & 60 & 5 & 3 \\
\hline Supply of Printed Stationeries & Product & 50 & 23 & 5 \\
\hline Supply of Fuel for Generators & Product & 50 & 25 & 8 \\
\hline Design and Construction of Metal Works Services & Product & 50 & 3 & 2 \\
\hline Supply and Maintenance of Security Doors & Product & 65 & 10 & 4 \\
\hline Supply of Signage Services & Service & 60 & 17 & 6 \\
\hline Supply of Architectural Design Services & Service & 65 & 9 & 4 \\
\hline $\begin{array}{l}\text { Supply of Civil Engineering/Construction and } \\
\text { General Building Management }\end{array}$ & Service & 80 & 63 & 16 \\
\hline $\begin{array}{l}\text { Supply of El ectrical a nd Mechanical Engineering } \\
\text { Design Services }\end{array}$ & Service & 70 & 12 & 4 \\
\hline Supply of Courier Services & Service & 75 & 21 & 6 \\
\hline Supply of Cleaning Services & Service & 70 & 39 & 8 \\
\hline Supply of Lifts a nd Es calator Ma intenance Services & Service & 50 & 3 & 2 \\
\hline Supply of Tra ining Aids a nd Related Equipment & Product & 50 & 5 & 5 \\
\hline Supply of Pa inting Services & Service & 50 & 9 & 4 \\
\hline $\begin{array}{l}\text { Supply and Maintenance of Desktop Computers and } \\
\text { Printers }\end{array}$ & Product & 75 & 32 & 13 \\
\hline
\end{tabular}




\begin{tabular}{|c|c|c|c|c|}
\hline Supply of Corporate Gifts & Product & 65 & 18 & 11 \\
\hline Supply of Haulage and Warehousing Se rvices & Service & 50 & 10 & 6 \\
\hline Supply of Se curity Guards & Service & 60 & 31 & 12 \\
\hline Supply of Motor Bikes & Product & 60 & 3 & 1 \\
\hline Supply of Water a nd Sewage Treatment Plants & Service & 50 & 4 & 2 \\
\hline $\begin{array}{l}\text { Supply, Installation and Maintenance of } \\
\text { Trans formers a nd Other Power Equipment }\end{array}$ & Product & 70 & 20 & 8 \\
\hline Supply of Motor Vehicles & Product & 50 & 6 & 5 \\
\hline \multicolumn{3}{|c|}{ TOTAL } & 494 & 170 \\
\hline
\end{tabular}

Table 2 presents the selection criteria and the associated weighting for each criterion. All responding potential suppliers were included in the qualification process and were scored on the basis of the evidence and information provided. For example, a potential supplier that could show that key members of staff had at least 12 years of experience in providing the relevant products or service was award 20 points while one that could only show 5-6 years of experience was awarded 8 points. Analysis of the data was carried out using SPSS. The use of statistical tests was necessary in order to show detailed and important differences between qualified and non-qualified potential suppliers across the range of criteria as well as differences between those suppliers that provided products and those that provided services.

Table 2. The criteria and their associated weightings

\begin{tabular}{|c|c|c|}
\hline Number & Criteria & Weighting (Maximum Mark) \\
\hline \multirow[t]{3}{*}{$\mathrm{A}$} & Ade quacy of legal a nd ci vic ca pabilities & $(8)$ \\
\hline & a) Legal & 5 \\
\hline & b) Civic & 3 \\
\hline B & $\begin{array}{l}\text { Ade quacy of Firm's s pecific and Ge neral experiences, resources and other } \\
\text { capabilities }\end{array}$ & $(62)$ \\
\hline \multirow[t]{4}{*}{ B1. } & $\begin{array}{l}\text { List of } 3 \text { recent job references carried out in the past } 3 \text { years (with verifiable } \\
\text { evidence) }\end{array}$ & (14) \\
\hline & a) 3 or more examples & 14 \\
\hline & 2 exa mples & 10 \\
\hline & c) 1 exa mple & 5 \\
\hline \multirow[t]{4}{*}{ B2. } & Management Capability with verifiable CVs & (20) \\
\hline & a) Keys taff of 12 yea rs experience and above & 20 \\
\hline & Keys taff of 7-11 years experience & 12 \\
\hline & c) Keys taff of 5-6 years experience & 8 \\
\hline \multirow[t]{3}{*}{ B3. } & EH\&Q Capability with verifiable policy and procedures & (12) \\
\hline & a) Quality policy and procedures & 4 \\
\hline & b) Health a nd Safety policy a nd procedures & 4 \\
\hline
\end{tabular}




\begin{tabular}{|c|c|c|}
\hline & Workmanship Insurance & 4 \\
\hline \multirow[t]{6}{*}{ B4. } & $\begin{array}{l}\text { Service and Flexibility capabilities (with verifiable evidence of locations and } \\
\text { affiliations) }\end{array}$ & (16) \\
\hline & a) Coverage of 3 keylocations (Lagos, $\mathrm{PH}$, Abuja) & 10 \\
\hline & Coverage of only 2 out of 3 keylocations & 6 \\
\hline & Coverage of one keylocation & 3 \\
\hline & Coverage of other locations & 2 \\
\hline & II. OEM a ffiliations & 4 \\
\hline \multirow[t]{3}{*}{$\mathrm{C}$} & Adequacy of Financial Capability & (30) \\
\hline & a) Adequacy of internally ge nerated funds & 30 \\
\hline & TOTAL SCORE FOR THE 3 CRITERIA & $(100)$ \\
\hline
\end{tabular}

\subsection{Study Validity}

The internal validity of a piece of action research is determined by the study's ability to identify and enable changes that lead to improvements in the organisation [30]. This study meets this condition since the preferred supplier list generated by the research is now in use at ServiceOrg who are now using centralised purchasing of major goods and services and a reduction in cost and operational risk to the organisation. An action research study will also be externally valid if it contains insights that can be generalised beyond the context within which it was studied. This study also satisfies this condition since the analysis identified the major shortcomings of unsuccessful bidders for major goods and services, and these would apply to other organisations in Nigeria that wish to implement a structured supplier selection process based on criteria similar to those of ServiceOrg.

The generalizability of this study is particularly enhanced by two factors; firstly, the invitation to potential suppliers was published nationwide through newspapers - this is common practice in the country as there are no national databases of organisations by sector. Therefore, the organisations that responded are those that are likely to respond to calls of this nature and their performance would be reflective of industry performance based on the selection criteria used by ServiceOrg. Secondly, the ranking of organisations 
was based on the evidence they provided and not on their perceived performance, as is the case with other research methods such as questionnaire surveys. Therefore, the results of the study reflect actual levels of performance and therefore enhance the generalizability, validity and reliability of the study's findings.

\section{Results}

The results of the analysis are summarised in the tables below. Table 3 summarises the mean, standard deviation and range for all companies across all criteria scores. It shows that on average, the performance of Nigerian suppliers exceeded $50 \%$ in 6 of the criteria except for Quality Policy and Procedures, Workmanship Insurance, Coverage of Locations, OEM Affiliations and Adequacy of Financial Capabilities. However, the 5 categories where average performance was below $50 \%$ account for 54 marks out of 100 based on ServiceOrg's criteria. The implication is that, overall, the performance of the organisations involved in the study is below par for the weighted majority of the criteria specified in the study.

Table 3. Means, standard deviations and ranges of results for all respondents.

\begin{tabular}{lccc}
\hline \multicolumn{1}{c}{ Category } & Mean & Std. Deviation & Range \\
\hline Adequacy of Legal Ca pabilities & & 0.66 & 5 \\
Adequacy of Civic Ca pabilities & 2.91 & 1.20 & 3 \\
List of 3 recent job references ca rried out in the & 12.10 & 3.92 & 14 \\
past 3 years & 11.64 & 7.78 & 20 \\
Management Capabilities & 1.69 & 1.89 & 4 \\
Quality Policy and Proce dures & 2.12 & 1.90 & 4 \\
Health and Safety Procedures & 1.94 & 1.99 & 4 \\
Workmanship Insurance & 3.52 & 2.57 & 10 \\
Service and Flexibility Capabilities & 0.45 & 0.83 & 2 \\
(Evidence of Locations) & 1.12 & 1.78 & 4 \\
Coverage of Other Locations & & & \\
OEM Affiliations & & & \\
\hline
\end{tabular}




\begin{tabular}{lllc}
\hline Ade quacy of Financial Capability & 13.12 & 12.46 & 30 \\
Total Score & 54.67 & 22.44 & 100 \\
\hline (Number of respondents $=494)$ & &
\end{tabular}

Table 4 shows the results of an independent t-test comparing qualified (i.e. organisations that achieved the minimum acceptable level of performance) and non-qualified suppliers (i.e. organisations that failed to achieve the minimum acceptable level of performance). The results indicate that there were significant differences between qualified and non-qualified suppliers in all eleven categories. The significance is that the qualified minority of suppliers, on average, appear to be doing almost everything right while the non-qualified majority appear to be doing almost everything wrong.

Table 4. Results of independent samples $t$ test - organisational performance in each category for all respondents (Qualified vs. non-Qualified).

\begin{tabular}{|c|c|c|c|c|c|c|}
\hline \multirow{3}{*}{ Category } & \multicolumn{6}{|c|}{ t-test for Equality of Means } \\
\hline & \multirow[t]{2}{*}{$\begin{array}{c}\text { Valid } \\
\text { Response }\end{array}$} & \multirow[t]{2}{*}{$T$} & \multirow[t]{2}{*}{$\mathrm{df}$} & \multirow[t]{2}{*}{ Sig. (2-tailed) } & \multicolumn{2}{|c|}{$\begin{array}{l}\text { 95\% Confidence Interval of } \\
\text { the Difference }\end{array}$} \\
\hline & & & & & Lower & Upper \\
\hline Adequacy of Legal Ca pabilities & 494 & -3.14 & 322.00 & 0.00 & -0.23 & -0.05 \\
\hline Ade quacy of Civic Ca pabilities & 494 & -4.61 & 414.88 & 0.00 & -0.69 & -0.28 \\
\hline $\begin{array}{l}\text { List of } 3 \text { recent job references ca rried out } \\
\text { in the past } 3 \text { years }\end{array}$ & 494 & -6.96 & 473.38 & 0.00 & -2.58 & -1.44 \\
\hline Management Capabilities & 494 & -13.32 & 449.76 & 0.00 & -8.95 & -6.65 \\
\hline Quality Policy a nd Proce dures & 494 & -8.66 & 333.02 & 0.00 & -1.80 & -1.13 \\
\hline Health and Safety Proce dures & 494 & -9.14 & 388.73 & 0.00 & -1.79 & -1.15 \\
\hline Workma nship Insurance & 494 & -7.05 & 361.84 & 0.00 & -1.60 & -0.90 \\
\hline $\begin{array}{l}\text { Service and Flexibility Capabilities } \\
\text { (Evidence of Locations) }\end{array}$ & 494 & -5.27 & 293.19 & 0.00 & -1.81 & -0.83 \\
\hline Coverage of Other Locations & 494 & -2.73 & 301.92 & 0.01 & -0.38 & -0.06 \\
\hline OEM Affiliations & 494 & -4.95 & 289.66 & 0.00 & -1.21 & -0.52 \\
\hline Adequacy of Financial Capability & 494 & -20.47 & 492.00 & 0.00 & -19.45 & -16.05 \\
\hline Total Score & 494 & -26.16 & 425.46 & 0.00 & -37.39 & -32.16 \\
\hline
\end{tabular}


This finding was contrary to the expectation of the research team and ServiceOrg. While significant differences were to be expected between qualified and non-qualified suppliers of such high value goods and services, the differences were not expected to be universal across all the criteria.

\subsection{Products vs. Services}

Table 5 presents the means, standard deviations and t-test analysis of all organisations based on whether they were product or service suppliers. The results from the 'means' analysis shows that service suppliers outperformed products suppliers in almost all categories except for Adequacy of Legal Capabilities (where the score were identical), List of 3 recent job references carried out in the past 3 years, and OEM Affiliations. The results suggest that service suppliers are more likely to have better internal systems, flexibility, management capability and financial stability. However, they are less likely to show evidence of previous jobs or have relationships with OEMs. The t-test results, however, show that there were statistically significant differences in only three criteria - Adequacy of Civic Capabilities, Quality Policy and Procedures, and Coverage of Other Locations. It is unclear why service companies are more likely to show evidence of paying taxes (civic responsibility) but their superior performance for possessing a Quality Policy may be because they bear primary responsibility for the quality of the service that they provide (for example courier services or security guards). Product suppliers on the other hand are more likely to be intermediaries and importers (from OEMs) and are not the primary producers (foe example motor vehicles, air conditioners, and computers); consequently, they may feel less need to have a quality policy. 
Table 5. Means and standard deviations of all organisations split by category and t-test results of organisational performance

(product or service).

\begin{tabular}{|c|c|c|c|c|c|c|c|c|}
\hline \multirow[t]{2}{*}{ Category } & \multicolumn{2}{|r|}{ Product } & \multicolumn{2}{|r|}{ Service } & \multicolumn{4}{|c|}{ t-test for Equality of Means } \\
\hline & Mean & Std. Deviation & Mean & Std. Deviation & Valid Response & $\mathrm{t}$ & df & Sig. (2-tailed) \\
\hline Adequacy of Legal Ca pabilities & 4.91 & 0.65 & 4.91 & 0.67 & 494 & -0.04 & 459.72 & 0.97 \\
\hline Ade quacy of Civic Ca pabilities & 1.98 & 1.22 & 2.20 & 1.16 & 494 & -2.06 & 492.00 & 0.04 \\
\hline List of 3 recent job references ca rried out in the past 3 years & 12.15 & 3.93 & 12.04 & 3.90 & 494 & 0.33 & 492.00 & 0.75 \\
\hline Management Capabilities & 11.26 & 7.53 & 12.11 & 8.09 & 494 & -1.19 & 449.54 & 0.23 \\
\hline Quality Policy a nd Proce dures & 1.51 & 1.88 & 1.92 & 1.89 & 494 & -2.41 & 492.00 & 0.02 \\
\hline Health a nd Safety Proce dures & 2.00 & 1.92 & 2.27 & 1.88 & 494 & -1.57 & 492.00 & 0.12 \\
\hline Workmanship Insurance & 1.88 & 1.99 & 2.02 & 1.99 & 494 & -0.74 & 492.00 & 0.46 \\
\hline $\begin{array}{l}\text { Service and Flexibility Ca pabilities } \\
\text { (Evidence of Locations) }\end{array}$ & 3.43 & 2.42 & 3.62 & 2.75 & 494 & -0.81 & 435.43 & 0.42 \\
\hline Coverage of Other Locations & 0.34 & 0.75 & 0.58 & 0.90 & 494 & -3.14 & 420.35 & 0.00 \\
\hline OEM Affiliations & 1.16 & 1.81 & 1.07 & 1.75 & 494 & 0.51 & 492.00 & 0.61 \\
\hline Adequacy of Financial Capability & 12.16 & 12.57 & 14.33 & 12.24 & 494 & -1.92 & 492.00 & 0.05 \\
\hline Total Score & 52.78 & 23.02 & 57.07 & 21.50 & 494 & -2.12 & 492.00 & 0.03 \\
\hline
\end{tabular}




\subsection{Products (qualified vs. non-qualified suppliers)}

Table 6 presents the results of an independent t-test investigating the differences in performance between qualified and non-qualified product suppliers. It shows that there are statistically significant differences between qualified and non-qualified suppliers across all eleven criteria. These findings suggest that there is a large variation in performance among Nigerian product suppliers that bid for such contracts, and again indicates a clear polarity between qualified and non-qualified suppliers. The implication is that a small number of product suppliers are doing everything right while the majority are doing everything wrong.

Table 6. Results of an independent samples t-test - organisational performance for all product organisations (Qualified vs. non-Qualified)

\begin{tabular}{|c|c|c|c|c|c|c|}
\hline \multirow{3}{*}{ Criteria } & \multirow{3}{*}{$\begin{array}{c}\text { Valid } \\
\text { Response }\end{array}$} & \multicolumn{5}{|c|}{ t-test for Equality of Means } \\
\hline & & \multirow[t]{2}{*}{$\mathrm{t}$} & \multirow[t]{2}{*}{$\mathrm{df}$} & \multirow[t]{2}{*}{$\begin{array}{l}\text { Sig. (2- } \\
\text { tailed) }\end{array}$} & \multicolumn{2}{|c|}{$\begin{array}{l}\text { 95\% Confidence Interval of } \\
\text { the Difference }\end{array}$} \\
\hline & & & & & Lower & Upper \\
\hline Adequacy of Legal Ca pabilities & 276 & -2.41 & 175.00 & 0.02 & -0.27 & -0.03 \\
\hline Ade quacy of Civic Ca pabilities & 276 & -4.10 & 236.65 & 0.00 & -0.86 & -0.30 \\
\hline $\begin{array}{l}\text { List of } 3 \text { recent job references ca rried out } \\
\text { in the past } 3 \text { years }\end{array}$ & 276 & -4.85 & 265.20 & 0.00 & -2.73 & -1.15 \\
\hline Management Capabilities & 276 & -10.31 & 244.30 & 0.00 & -9.41 & -6.39 \\
\hline Qual ity Policy and Proce dures & 276 & -8.07 & 180.42 & 0.00 & -2.20 & -1.34 \\
\hline Health and Safety Proce dures & 276 & -9.52 & 234.07 & 0.00 & -2.32 & -1.52 \\
\hline Workmanship Insurance & 276 & -6.59 & 274.00 & 0.00 & -1.99 & -1.07 \\
\hline $\begin{array}{l}\text { Service and Flexibility Capabilities } \\
\text { (Evidence of Locations) }\end{array}$ & 276 & -4.03 & 182.34 & 0.00 & -1.84 & -0.63 \\
\hline Coverage of Other Locations & 276 & -3.26 & 155.12 & 0.00 & -0.53 & -0.13 \\
\hline OEM Affiliations & 276 & -4.22 & 171.51 & 0.00 & -1.44 & -0.52 \\
\hline Adequacy of Financial Capability & 276 & -17.44 & 174.15 & 0.00 & -21.62 & -17.23 \\
\hline Total Score & 276 & -21.32 & 274.00 & 0.00 & -41.25 & -34.28 \\
\hline
\end{tabular}




\subsection{Services (qualified vs. non-qualified suppliers)}

Table 7 presents the results of a t-test investigating the differences between qualified and non-qualified service suppliers. It shows that there are statistically significant differences in nine of the eleven criteria - Adequacy of Civic Capabilities, List of 3 recent job references carried out in the past 3 years, Management Capabilities, Quality Policy and Procedures, Health and Safety Procedures, Workmanship Insurance, Service and Flexibility Capabilities, OEM Affiliations and Adequacy of Financial Capability. Similar to the results of the product suppliers, these findings suggest that there is a large variation in performance between the minority of potential suppliers who perform well and the majority that perform poorly. However, unlike product suppliers the significant differences did not span all criteria, as the analysis did not show statistically significant differences in the two criteria of Adequacy of Legal Capabilities, and Coverage of Other Locations.

Table 7. Results of an independent samples t-test - organisational performance for all service organisations (Qualified vs. non-Qualified).

\begin{tabular}{|c|c|c|c|c|c|c|}
\hline \multirow{3}{*}{ Criteria } & & \multicolumn{5}{|c|}{ t-test for Equality of Means } \\
\hline & \multirow[t]{2}{*}{ Valid Response } & \multirow[t]{2}{*}{$\mathrm{t}$} & \multirow[t]{2}{*}{$\mathrm{df}$} & \multirow[t]{2}{*}{$\begin{array}{l}\text { Sig. (2- } \\
\text { tailed) }\end{array}$} & \multicolumn{2}{|c|}{$\begin{array}{l}\text { 95\% Confidence Interval of the } \\
\text { Difference }\end{array}$} \\
\hline & & & & & Lower & Upper \\
\hline Adequacy of Legal Ca pabilities & 218 & -2.02 & 146.00 & 0.05 & -0.27 & 0.00 \\
\hline Ade quacy of Civic Ca pabilities & 218 & -2.42 & 174.66 & 0.02 & -0.67 & -0.07 \\
\hline $\begin{array}{l}\text { List of } 3 \text { recent job references ca rried out } \\
\text { in the past } 3 \text { years }\end{array}$ & 218 & -5.07 & 203.11 & 0.00 & -2.91 & -1.28 \\
\hline Management Capabilities & 218 & -8.69 & 202.15 & 0.00 & -9.54 & -6.01 \\
\hline Quality Policy a nd Proce dures & 218 & -4.17 & 216.00 & 0.00 & -1.62 & -0.58 \\
\hline Health and Safety Proce dures & 218 & -3.48 & 147.66 & 0.00 & -1.41 & -0.39 \\
\hline Workmanship Insurance & 218 & -3.21 & 144.10 & 0.00 & -1.44 & -0.34 \\
\hline $\begin{array}{l}\text { Service and Flexibility Capabilities } \\
\text { (Evidence of Locations) }\end{array}$ & 218 & -3.45 & 111.60 & 0.00 & -2.29 & -0.62 \\
\hline Coverage of Other Locations & 218 & -0.80 & 216.00 & 0.43 & -0.36 & 0.15 \\
\hline OEM Affiliations & 218 & -2.65 & 116.81 & 0.01 & -1.23 & -0.18 \\
\hline Adequacy of Financial Capability & 218 & -12.08 & 169.40 & 0.00 & -18.36 & -13.20 \\
\hline Total Score & 218 & -15.29 & 181.04 & 0.00 & -35.35 & -27.27 \\
\hline
\end{tabular}




\section{Discussion}

Although, the overall mean for all 494 bids was above average (considering the range of 0 100) at 54.67, a more detailed analysis of performance provides interesting insights. From Table 1, the failure of the overwhelming majority of bids to achieve the minimum performance required by the ServiceOrg suggests that there are significant weaknesses in most Nigerian supplier organisations of high value goods and services. The t-test indicated that there were significant differences in all categories between the organisations that achieved the minimum performance and those that failed to do so. The clear implication is that a small number of supplier organisations are achieving significantly higher performance across the board (based on ServiceOrg's criteria) in comparison to the majority of the potential supplier base. Tables 6 and 7 further confirm that this is the case irrespective of whether the organisations are product or service suppliers. The findings have important implications for the developmental needs and competitiveness of the Nigerian market.

\subsection{Competitiveness of Suppliers in the Nigerian Market}

The large numbers of organisations seeking the status of qualified suppliers would suggest that there is a healthy level of competitiveness in the Nigerian marketplace. This would be the case if the qualification exercise and the associated criteria set by ServiceOrg had not been applied. The qualification exercise, combined with the major differences between qualified and non-qualified potential suppliers and the subsequent exclusion of the significant majority of potential suppliers, clearly indicates that the competitiveness of organisations reduced vastly when even the most basic discriminating criteria (e.g. health and safety procedures, registration as legal business organisation, evidence of tax payment) 
are applied. The findings from this study confirm the suggestion by Sarkar and Mohapatra [33] that sourcing decisions should be based on a wide range of criteria including technological, financial and quality systems. The study further noted that using such criteria can help to identify suppliers with long-term capabilities. Bearing in mind the financial stability and operational quality criteria demanded by ServiceOrg, the suggestion is that the qualification exercise has been successful in separating the stronger suppliers from the weaker suppliers and that these stronger suppliers are likely to possess long-term capabilities. While prequalification has been used widely for large public projects in Nigeria [34], this project finds that it can also be applied successfully in private sector non-project procurement and can achieve the same goal of preventing "fronting and window dressing" [34] by ensuring that suppliers that eventually tender have the capability to deliver.

The fact that the non-qualified potential suppliers included organisations that were legacy suppliers leads to the consideration of the existence of (or lack of) entry barriers from a competitiveness point of view. Based on the findings in this study, the authors suggest that, at a basic level, the Nigerian market is competitive with many potential suppliers vying to be considered for a variety of products and services. This, in part, could be because there is a threat of new entrants since there are very few barriers to entry for many products and services. For example, since products are not typically supplied directly by OEMs, then, in theory and practice, any organisation could set itself up as an intermediary. According to [26], the ability of new entrants to enter the market increases the competition and this is aptly demonstrates the situation of Nigerian suppliers in the absence of qualifying criteria.

However Porter [26] also stressed that high barriers to entry reduce the level of competition and improves the competitive positioning of organisations in the market. 
Therefore, by introducing qualification criteria, ServiceOrg has significantly altered the market by creating barriers to entry. The implication for the Nigerian market is that most suppliers are unable to meet these criteria and are excluded from the market. Therefore barriers to entry suggested by Porter [26] have a very significant impact on competition and competitiveness in the Nigerian market. For example, from a marketplace of thousands of generator suppliers, only 34 potential suppliers applied for qualification and only 5 achieved the minimum acceptable performance.

\subsection{Competitiveness of ServiceOrg as a result of the qualification exercise}

Ironically, by rightly specifying that its potential suppliers meet a minimum level of performance as identified in the criteria determined, ServiceOrg may have weakened its position in certain instances. For example, there was only one qualified potential supplier for motorbikes and two each for sewage treatment plants, lift and escalator maintenance services, and construction of metal work. There were also a low level of qualifying organisations for other goods and services such as painting services, toners, electrical and mechanical engineering services. Once again, from the perspective of Porter's five forces, the qualification exercise could have reduced the bargaining power of ServiceOrg while increasing the bargaining power of the few qualified suppliers. Consequently, the qualification exercise has introduced new barriers to entry that would not only significantly alter the competitive position of ServiceOrg and its suppliers, but could also impact the way in which relationships with key suppliers are managed. For example, for products and services which are crucial to operations but have few qualified suppliers, there is a clear need to work more closely with the few qualified suppliers in order to avoid or minimise 
disruption to operations. This is in line with the suggestion by Jain et al [35] that buyersupplier relationships should be based on cooperation and collaboration. Furthermore the study by Jain et al [35] justified the approach by ServiceOrg by suggesting that preferred suppliers should be chosen based on criteria that go beyond cost and which involve supplier competencies.

The challenges of location flexibility could provide ServiceOrg with interesting options. One of these could be to specify the need to service these locations as part of an agreement with suppliers at the contract stage and agree any premiums in pricing. Alternatively, in the case that qualified suppliers blatantly do not have the ability to service remote locations, ServiceOrg may consider lowering the minimum acceptable performance in order to contract more local suppliers. While this may be easy for some of the commoditized products and services (e.g. supply of printed stationery), it may be more difficult to find local suppliers for more specialist products and services (e.g. supply of lifts and escalator maintenance services) even if the minimum acceptable performance was reduced.

A potential impact of the qualification exercise would be to improve the cost base of ServiceOrg, improve its image and services to its clients and, consequently, reduce its cost of operations. This would, in turn, make it more competitive in comparison to its competitors from the perspective of the shareholders, who gain the cost reduction benefits, and the clients who receive more reliable services. However, to achieve these benefits, the organisation would need to overcome the challenges that arise with have a reduced supplier base with more bargaining power and the servicing of remote locations. 


\subsection{Performance of Nigerian Suppliers}

The findings from the study clearly suggest that there are few or no generic strengths and weaknesses of Nigerian suppliers based on the criteria used by ServiceOrg. Rather, the market is characterised by a minority of suppliers that appear to do almost everything right and a majority that appear to do almost everything poorly, irrespective of whether they are product or service suppliers. However, the clear differences between the good minority and the poor majority confirm the validity of the criteria used in selection. In many respects, some of the results were unexpected by the research team and ServiceOrg. The expectation had been that there would be no significant differences between qualified and non-qualified organisations for some criteria such as quality policy and procedures, health and safety policy and procedures, workmanship insurance and adequacy of legal capabilities. This expectation was based on the assumption that all potential suppliers that would be interested in becoming qualified suppliers of such high value products and services (which are very specialised in some cases) would be well established business entities which would be expected, as a minimum, to achieve certain basic criteria. This expectation partly influenced the decision to place more emphasis on financial stability and management capabilities in the determination of the scoring matrix used for qualification. When comparing the criteria used in this study with the criteria studied by Har and Pani [36], it is clear to see that criteria such as quality management systems and employee management can be important discriminators even though Har and Pani [36] found that they were not highly regarded in the context of a different developing country. Therefore, the emphasis placed on different criteria in the selection process may differ from place to place and may ultimately lead to different supplier base cultures. 
However, given that many potential suppliers have performed poorly across the board in this exercise, the question arises about whether the same result could have been achieved by using less qualification criteria. While this will depend greatly on the specific criteria selected, the authors would suggest that a reduction in criteria would increase risk to ServiceOrg's operation and reputation. To provide discrimination, reduced criteria would have to prioritize factors such as adequacy of financial capability and management capability which possess the highest standard deviations while excluding factors such as adequacy of legal capabilities, workmanship insurance, health and safety procedures as well as quality policy and procedures. The danger therefore exists, that potential suppliers with good management experience and financial base would be qualified but could, in theory, carry a risk of lacking a combination of the excluded factors. Such a risk could be very expensive and damaging if there were to be problems and/or injury/fatality in, for example, the construction of buildings, installation of transformers and power equipment and installation/maintenance of lifts.

The findings provide a clear insight into the developmental needs of the majority of Nigerian suppliers of high value products and services. It suggests the need for wide ranging improvement in capability and performance. This is in line with the suggestion by Sakar and Mohapatra [33] that performance and capability should be the key dimensions for evaluating suppliers. The categories for improvement range from basic legal requirements (proper registration of businesses) to improving their financial stability, business flexibility, technical skills and experience as well as process management (e.g. quality procedures) and corporate social responsibility (e.g. workmanship insurance, evidence of tax payment). Failure to improve may imply that competition for the most coveted contracts, which 
increasingly require pre-qualification, will be stifled and the few potential suppliers that appear to be doing everything right may dominate the market for such high value, high margin products and services. The findings also have important implications for governmental organisations and their activities. One of these is the need to bolster awareness of organisations to improve competitiveness by addressing the weaknesses identified in this study. There is also the potential for government agencies to bolster the development of competencies by promoting training and skills acquisition aimed at areas of weakness. In addition, there may be a need to introduce or improve enforcement of regulatory measures that compel organisations to improve important factors such as health and safety procedures and workmanship insurance which have a direct and significant socioeconomic consequences and impact on employee well-being and performance. While not considered in this study, it would be important to understand if societal and sustainability factors such as environmental sustainability are influential factors for qualifying suppliers in countries such as Nigeria. This could be considered in future studies. Follow-up studies could also investigate the actual service delivery by qualified suppliers and compare this with the expectations generated in the qualification exercise as well as performance of nonqualified suppliers.

\section{Conclusions}

The main aims of the study were to investigate and demonstrate the importance of the qualification phase in supplier selection and to provide an insight into purchasing in Nigeria. The study has shown that the qualification phase is crucial in discriminating the good few from the poor many. It has also shown that the differences between these two classes span 
a wide range of criteria and that the developmental needs are significant for the many potential suppliers that fail to be qualified. The study has also shown that the Nigerian market can be very competitive with few entry barriers when there are no qualifying criteria in place. However, the specification of qualifying criteria changes the potential level of competition dramatically.

It is important at this point to revisit the study's research questions. Research Question 1 sought to identify the level of performance of Nigerian organisations when assessed against criteria set by a customer. The study has shown that the overall levels of performance differ for different criteria and that performance levels are variable across the spectrum of products and services considered. Research Question 2 sought to differentiate between qualified and non-qualified suppliers. The study has shown clear differences between the qualified few and the non-qualified many. Research Question 3 sought to understand the impact of performance on competitive positioning. The study has argued that, based on the qualification of only a few potential suppliers, the competitive positioning and bargaining power of both ServiceOrg and its suppliers could alter greatly as a result of the qualification exercise. Finally, Research Question 4 sought to understand developmental priorities of Nigerian suppliers. The study has shown that there are few generic strengths across the board and multiple areas of development need to be addressed in order to improve competitiveness of the supplier base.

The findings have important industrial and academic implications. For industry, there is a need for potential suppliers to understand the need for improving their capabilities if they are to be considered by increasingly demanding customers such as ServiceOrg. For the customers, there is need to recognise that while a qualification process may imply that they 
identify the best suppliers, it may also lead to a very significant reduction in competition and, potentially, a reduction in their bargaining power. Academically, it is clear that there is a need to carry out more purchasing research in developing economies where the business landscape can be quite different to developed economies and where developmental opportunities need to be identified. The authors would suggest that the study's findings may be applicable in other developing economies.

This paper concludes by identifying the study limitations. This study was based on criteria specific to ServiceOrg and did not include factors that other organisations and researchers may wish to consider (e.g. lead times). Furthermore, while ServiceOrg now deals with the qualified suppliers, performance at the tender and delivery stages as well as information on specific suppliers and contracts are not available for analysis. Thus it is not possible compare the performance of legacy suppliers and new suppliers. In addition, the study did not compare the implications that varying the level of minimum acceptable performance would have had on the numbers of qualified suppliers. Such sensitivity analysis was outside the scope of this study and could be the subject of future studies.

\section{Acknowledgement}

This work was supported by the Higher Education Research Promotion, National Research University Project of Thailand, Office of Higher Education Commission, and Thammasat Business School, Thammasat University. 


\section{References}

[1] SMART, A. \& DUDAS, A. 2007, Developing a decision-making framework for implementing purchasing strategy. International Journal of Physical Distribution and Logistics Management, 37, 64-89.

[2] MEEHAN, J. and WRIGHT, G. H. 2011, Power priorities: A buyer-seller comparison of areas of influence. Journal of Purchasing and Supply Management, 17, 32-41.

[3] GOOLD, M. and CAMPBELL, A. 2000, Taking stock of synergy, a framework of assessing linkages between businesses. Long Range Planning, 33, 72-96.

[4] MSIMANGRIA, K. 2003, Purchasing and supply chain management practices in Botswana. Supply Chain Management: An International Journal, 8, 7-11.

[5] SWINDER, J. and SRIVATSA, S. 2001, The influence of purchasing strategies on performance. Journal of Business and Industrial Marketing, 16, 294-308.

[6] OKAFOR, E. 2008, Development crisis of power supply and implications for industrial sector in Nigeria. Studies of Tribes and Tribals, 6, 83-92.

[7] OLUFEMI, A. 2009, Managing organizational change in Nigerian manufacturing ente rprises: lessons from Unilever Plc. International Business Management, 3, 15-21.

[8] HO, W., DEY, P. and LOCKSTROM, M. 2011, Strategic sourcing: a combined QFD and AHP approach in manufacturing. Supply Chain Management: An International Journal, 16, 446-461.

[9] HARTMANN, A. and CAERTELING, J. 2010, Subcontractor procurement in construction: the interplay of price and trust. Supply Chain Management: An International Journal, 15, 354-362.

[10] HSU, C.-C., KANNAN, V. R., LEONG, G. K. and TAN, K.-C. 2006, Supplier selection construct: instrument development and validation. The International Journal of Logistics Management, 17, 213-239. 
[11] BOTTANI E., RIZZI A., and VIGNALI G. 2015, Improving logistics efficiency of industrial districts: a framework and case study in the food sector. International Journal of Logistics: Research and Applications, 18, 402-423.

[12] ALLAL-CHERIF, O. and MAIRA, S. 2011, Collaboration as an anti-crisis solution: the role of the procurement function. International Journal of Physical Distribution and Log istics Management, 41, 860-877.

[13] CARTER, J. R., MALTZ, A., MALTZ, E., GOH, M. and YAN, T. 2010, Impact of culture on supplier selection decision making. The International Journal of Logistics Management, 21, 353-374.

[14] VOSS, D. 2013, Supplier choice criteria and the security aware food purchasing manager. International Journal of Logistics Management, 24, 380-406.

[15] PAL, A., CHAN, F., MAHANTY, B. and TIWARI, M. 2011, Aggregate procurement, production, and shipment planning decision problem for a three-echelon supply chain using swarm-based heuristics. International Journal of Production Research, 49, 2873-2905.

[16] LIU X., Wu, Y-C J., and GOH, M., 2016, Collaborative academic-industry SCM research and knowledge building. International Journal of Logistcis: Research and Applications, 19, 19-40.

[17] KATHURIA, R., PORTH, S., KATHUTIA, N. and KOHLI, T. 2010b, Competitive priorities and strategic consensus in emerging economies: evidence from India. International Journal of Operations and Production Management, 30, 879-876.

[18] KATHURIA, R., PARTOVI, F. and GREENHAUS, J. 2010a, Leadership practices, competitive priorities, and manufacturing group performance. International Journal of Operations and Production Management, 30, 1080-1105.

[19] HALLGREN, M., OLHAGER, J. and SCHROEDER, R. 2011, A hybrid model of competitive capabilities. International Journal of Operations and Production Management, 30, 511-526.

[20] HORTE, S. and YLINENPAA, H. 1997, The firm's and its customers' views on order-winning criteria. International Journal of Operations and Production Management, 17, 1006-1019. 
[21] QUESADA, G., RACHAMADUGU, R., GONZALEZ, M. \& MARTINEZ, J. 2008, Linking order winning and external supply chain integration strategies. Supply Chain Management: An International Journal, 13, 296-303.

[22] HILL, T. 1995, Manufacturing Strategy: Texts and Cases, Basingstoke, Macmillan.

[23] BOMMER, M., O'NEIL, B. and TREAT, S. 2001, Strategic assessment of the supply chain interface: a beverage industry case study. International Journal of Physical Distribution and Logistics Management, 31, 11-25.

[24] AITKEN, J., CHILDERHOUSE, P., CHRISTOPHER, M. and TOWILL, D. 2005, Designing and managing multiple pipelines. Journal of Business Logistics, 26, 73-95.

[25] PORTER, M. 1980, Competitive Strategy: Techniques for analyzing industries and competitors, New York, Free Press

[26] PORTER, M. 1985, Competitive Advantage: Creating and Sustaining Superior Performance, New York, Free Press.

[27] PORTER, M. 2001, Strategy and the Internet. Harvard Business Review, 79, 63-78.

[28] WORLD BANK. 2012, World Bank Development Indicators: Nigeria [Online]. Available: http://data.worldbank.org/country/nigeria [Accessed 02/03/2012.

[29] OKONJO-IWEALA, N. and OSAFO-KWAAKO, P. 2007, Nigeria's Economic Reforms: Progress and Challenges, Brookings Global Economy and Development - Working Paper No. 6. Washington: The Brookings Institution.

[30] BURNS, R. 2000, Introduction to Research Method, London, UK, Sage Publications.

[31] FRANKFORT-NACHMIAS, C. and NACHMIAS, D. 1992, Research Methods in the Social Sciences, London, Taylor and Francis.

[32] DE BOER, L., LABRO, E. and MORLACCHI, P. 2001, A review of methods supporting supplier selection. European Journal of Purchasing and Supply Management, 7, 75-89.

[33] SARKAR, A. and MOHAPATRA, P. 2006. Evaluation of supplier capability and performance: A method for supply base reduction. Journal of Purchasing and Supply Management, 12, 148-163. 
[34] ADEDOKUN, O., IBIRONKE, O and BABATUNDE, S. 2013. Assessment of competitive tendering methods of procuring educational building projects in Nigeria, Journal of Facilities Management, $11,81-94$

[35] JAIN, V., WADHWA, S. and DESHMUKH, S. 2009. Select supplier-related issues in modelling a supply chain: potential, challenges and direction for future research, International Journal of Production Research, 47, 3013-3039.

[36] HAR, A. and PANI, A. 2014. Exploring the importance of different supplier selection criteria, Management Research Review, 37, 89-105 